\title{
Teaching Innovation and Exploration of Electromagnetic Field and Electromagnetic Wave Course
}

\author{
Hui Zhang ${ }^{1, a^{*}}$, Dan Ren ${ }^{2}$, Jing Dai ${ }^{1}$ and Zhili Chen ${ }^{1}$ \\ ${ }^{1}$ School of Information \& Control Engineering, Shenyang Jianzhu University, Shenyang, China \\ ${ }^{2}$ College of engineering and technology, Eastern Liaoning University, Dandong, China \\ aarnold0110@sina.com
}

Keywords: Electromagnetic field and electromagnetic wave; Educational reform; Teaching method; Course reform

\begin{abstract}
As an important professional basic course for communication engineering major in university. Electromagnetic Field and Electromagnetic Wave is characterized by concepts abstract and theoretical derivation triviality. However, traditional teaching of this course pays more attention to theory than practice, while ignoring developing application ability of students. Which cause the students' actual application ability cannot be improved, and appears to be loss of interest in learning. Due to the difficult to teach and difficult to learn. In this paper, reform and innovation course Electromagnetic Field and Electromagnetic Wave on the provincial level are carried out in the aspects of teaching content, teaching methods, experiment teaching, and construction of teaching materials, etc. Some achievement and several revelations have received. Good example can be expressed for the construction of other courses.
\end{abstract}

\section{Introduction}

Electromagnetic Field and Electromagnetic Wave course is not only one of the important basic courses for the undergraduates major in communication engineering, electronic information and other speciality, but also one of the basic knowledge for the research workers who engaged in communications, electronics and other related fields[1,2]. The quantity of talented people majored in high-speed digital circuit, wireless communication and electromagnetic compatibility are increasing rapidly with the development of electronic information technology, the electromagnetic field theory has found an increasingly wide utilization in communication, remote sensing, radar and the electric control field .

Electromagnetic Field and Electromagnetic Wave is one of the main specialized basic courses for communication engineering in our school, which opened in the first semester of junior year for communications engineering professional students. Its advance courses are circuit theory, higher mathematics, and college physics, etc[3]. The teaching effect is directly related to the subsequent courses learning, such as antenna and wave propagation, the mobile communication technology and other professional courses. This course characteristics are deeply theoretical knowledge and strong professional,high requirement to the mathematics application ability, and the basic theory not closely with practical application, etc. Students generally feel the course difficult to understand, and difficult to learn. therefore, how to improve the Electromagnetic Field and Electromagnetic Wave course teaching quality, train and enhance the students ability to analyze the question and solve the actual problem, have been the majority problem to explore for teachers. As the leading teacher of Electromagnetic Field and Electromagnetic Wave course, our teaching team members have been exploration, reform and construction in electromagnetic field course teaching contents, teaching methods, and practice link, etc . 


\section{Deepen Teaching Research and Teaching Reform}

Selected Teaching Material, Reasonable Arrangement of Teaching Content. Course content reform maintains structural integrity and scientific of curriculum system [4]. Traditional electromagnetic theory and modern technology are taken account of in its contents. At the same time, the advancement and novelty of the content is emphasized in teaching reform. Teaching material is the expression of the course content including the inner thoughts, methods, evolution, etc, it is important basis for teaching, and is the important source of information for students learning. After comparing many excellent teaching materials in domestic and foreign country, we chose the electromagnetic field and electromagnetic wave (the Third Edition)textbook, the teaching material is compiled by Jiali Wang (he as the chief editor), published by Xi'an University of Electronic Science and technology press. This teaching material content is refined, theoretical framework is clear, and has many examples. The other material content such as electromagnetic field and electromagnetic wave which edited by Rugui Yang is concise and to the point, explain profound theories in simple language, so we select it as an after-school reference materials to meet the various levels of the students' learning. In the process of making the teaching syllabus. Teaching materials combine the specific characteristics and requirements of professional teaching, followed the development direction of new theories, new technology, so the syllabus will be revised after every two years practice teaching.

Course content reform maintains structural integrity and scientific of curriculum system. Traditional electromagnetic field theory and modern electromagnetic technology are taken account of in its contents. At the same time, the advancement and novelty of the content is emphasized in teaching reform. Electromagnetic field and electromagnetic wave course is mainly focused on the content of the static electric field, the constant current magnetic field, time-varying electromagnetic field and electromagnetic wave radiation, guided electromagnetic waves, etc[5]. Athough each module knowledge vary widely, but they are based on Maxwell's equations to achieve. According to the training target of professional talents as well as combining the current electromagnetic field and wave technology in industry, we grasp Maxwell's equations as the main line in the teaching : using Gauss theorem and Ampere's circulation theorem to analysis the static charge, the electromagnetic field generated by constant current, and the energy conversion relations between electric field energy and magnetic energy each other; discussing on the characteristics and principles of the plane electromagnetic wave and the time-varying electromagnetic field, energy conversion and conservation based on Faraday's law of induction and circuital law, the definition and solution of electric field intensity, electric displacement vector, magnetic induction, magnetic field and Poynting vector as a guide in electromagnetic field, to make the content of the electric and magnetic fields from independently to contact each other, finally to combine various fields into a complete system of electromagnetic field.

We show teaching important points in the class such as various vector, the application of theorem. from the perspective of "field" to derived theorem, explain problems and solve problems. In the teaching of the concrete application of the theorem, teacher should be good at fanning out from point to area, draw inferences about other cases from one instance, and comprehend by analogy. Because the course has more mathematical deduction, according to the actual application situation, students don't need to fully master the each vector mathematical derivation, in this section we explain the key knowledge points in detail, focusing on the solving methods of specific problems, such as the application of Gauss theorem and Stokes law etc, let students grasp the basic function of the field quantities and using method, avoids students feeling bored.

Now the teaching materials related content presented the development history of electromagnetic field theory and the electromagnetic phenomena application are rarely[6]. So the course teaching group has appropriate increased the content of the electromagnetic wave application, such as in the first chapter introduces the history of the development of electromagnetic field theory, introduces Faraday, Hertz, Maxwell's photo and personal narratives, and the invention contribution in the electromagnetic field, etc. With the development of mobile communication, modern communication 
tends to develop in the network, broadband and intelligent, according to the training target of professional talents as well as combining the current electronic measurement technology in industry, the course teaching group also increase the contents of the electromagnetic wave in practical application, In the static magnetic field chapter, explains engineering application examples of magnetic separation; in the electromagnetic induction chapter, introduces magnetic levitation technology; the plane electromagnetic wave contacts the microwave heating food; the electromagnetic wave applications in the field of radar, mobile communications. Through specific examples causes the student to understand the development of the electromagnetic field in time, improve students enthusiasm of learning.

Holding lectures on special topics of electromagnetic wave make course teaching rise to a higher level [7]. The lecture content includes reporting of researchers' latest research results and new industrial applications technology for new industrial applications for electromagnetic field and electromagnetic wave from domestic to foreign frontier. Students can comprehend the engineering application, latest development and future development trend of electromagnetic field and wave.

Enriching Teaching Methods, Improving Teaching Quality. Rich teaching method is an important way to realize the teaching purpose and improve the teaching quality. Electromagnetic field and electromagnetic wave theory course is a subject of a lot of theoretical knowledge, and tedious formula derivation, students who have a solid basic knowledge of higher mathematics and physics can understand much easier to master. For this reason, teachers must fully understand the students have mastered the skilled level of the knowledge points and utilization ability. When it comes to new content of courses, we use the related knowledge of advanced placement to be elaborated and instructed, avoid directly introduce the profound and difficult points. Because some students' basic knowledge is not strong, class teaching adopts to review firstly, explains the relevant mathematics vector calculation, double integrals and so on, enable students to understand and accept the new knowledge. In the teaching guide students to firmly grasp the content of the vector analysis, first set up the concept of vector, a scalar field, understanding and flexible computing divergence, curl and gradient in three coordinate system. For fields with different space distribution characteristics, required students can master and use Gauss theorem or Stokes theorem to solve problems, lay the foundation for subsequent chapters content.

The teaching method is a way that can present teaching content and decide the order of presentation. Appropriate teaching methods can not only create a proper atmosphere, crucially also affect the quality of teaching[8,9]. To improving teaching methods in teaching and considering the students actual situation, we change the teacher as the main body of the teaching in traditional teaching mode, Classroom teaching mainly uses the multimedia, the blackboard lecture as the assistant. Traditional teaching tool blackboard provides the main teaching content, some important theorems are derived by way of blackboard writing, so that we can deepen students' understanding of the theorem. Classroom teaching makes full use of multimedia courseware to realize illustrated and vividly convey knowledge to students through the auditory and visual, make students willing to accept, understand knowledge more thoroughly. The abstraction of teaching contents such as the polarization wave, the time-varying electromagnetic wave, the electric field distribution adopt flash animation, effectively enhance the teaching effect. Collected a part of the electromagnetic field video for students to learn, such as the rocket launch, the polarization application on satellite, radar, etc. Multimedia teaching mean has expanded the students' thinking space, promoted the effective use of classroom teaching and stimulate the students' learning enthusiasm.

Enriching Teaching Resources, Improving Learning Initiative. Some rich online instructional resources of this course are provided based on "electromagnetic field and electromagnetic wave study garden". Internet is changed into an effective education environment by this means. It can meet the demand of different level students and motivate students to master the electromagnetic system knowledge. Functions of the network education platform are summarized as follows: teaching focus and difficulty and learning instruction discuss the teaching aims and requirements of this course; Electronic after-school practice and multimedia courseware are made into web resource, it is a very 
convenient way for students to review lessons or realize independent learning. Students can do self-testing to check the comprehension degree of the course. At the same time, teachers can also organize mock examination regularly to check the stage learning effect of students and understand their mastery degree on related knowledge. The online resources also include the development of electromagnetic field theory in current society; electromagnetic application in military and daily life; and the calendar year postgraduate entrance examination question of electromagnetic field and electromagnetic wave for universities communications professional and so on .Students can easily navigate using on spare time, help students spend less time to master relevant knowledge of electromagnetic field.

\section{Strengthening the Construction of Practical System}

Practice teaching innovation is an important part in course reform. Practical teaching can solve the conflict between abstract and concrete in electromagnetic field teaching; Overcome the problems of theory detached from practice[10]. On the one hand, the students' basic skills, knowledge comprehensive application ability, independent analysis, solving problem and group cooperation spirit ability can be better cultivated through practice teaching; on the other hand, to lay a good foundation for subsequent courses, such as microwave technology, antenna and wave propagation. Reformed experiment content integrates normal experiment means, virtual instrument experiment means and verifiability, comprehensive experiment teaching methods availably, thus the shortage of traditional experiment is made up and the problems from current practice teaching are solved effectively. In order to arouse the students enthusiasm to do experiments, added some designing experiment content. For example, the mobile signal field strength characteristics experiment offers to students, students need search information, choose different buildings on campus (teaching building, dormitory buildings, laboratory buildings, etc.) to independent analysis the building penetration loss varies with frequency, The guide teachers only do necessary explanation, just give individual tutoring to students who are having difficulties throughout the process. Through practical training, improve the students' ability to analyze and deal with the experiment result, and stimulate the students' interest in experiment and cultivate of independent thinking, innovation and collaboration.

\section{Conclusion}

With the rapid development of science and technology, the application of electromagnetic field has been changing with each passing day. However, this reform will be a continuous process, teaching team need to follow the rules of teaching, further improve the teaching quality. We hope that electromagnetic field and electromagnetic wave course reform is more suitable for requirement of society.

\section{References}

[1] J. H. Zhou: Science and Innovation, (2015) No.15, p.131.

[2] X. F. Zhou, S. Qian, and Q. L. Li: China Electric Power Education, Vol. 191 (2011) No.4, p.68.

[3] Y. P. Chen: Asian Social Science, Vol. 6(2010), No. 11, p.209

[4] F. Zhou; Higher Education of Social ,Vol. 4 (2013) No. 1, p. 15.

[5] W. J. Li: Electromagnetic Field and Electromagnetic Wave (Xi'an Electronic and Science University Press, 2012).

[6] G. Jin: Journal of Science of Teachers' College and University, (2012) No.7, p.94.

[7] R. Q. Chen, and J. C. LI: Procedia Engineering, Vol. 29 (2012) ,p.94.Y. P. Chen: Asian Social Science, Vol. 6(2010), No. 11, p.209. 
[8] Y. H. Wang: Higher Education of Social Science Vol. 6 (2014), No.3, p. 71.

[9] W. Q. Wang, X. M. Sun and H.H. Wang: University Physics, Vol. 31(2012)No.12, p.27.

[10]Z. H. He and G. G. He: Advances in Physical Education, Vol.4(2014) No.1, p.36. 